\title{
Lesson learned from retaining wall failures: a geotechnical disaster
}

\author{
Aswin $\operatorname{Lim}^{1, *}$ \\ ${ }^{1}$ Parahyangan Catholic University, Civil Engineering Department, 40141, Jl. Ciumbuleuit 94, Bandung, Indonesia
}

\begin{abstract}
This article presents five failure cases of retaining wall which is obtained from literature and some personal documentation. One case is located in Singapore, two cases are located in Taiwan, and the other two cases are located in Indonesia. Among those five cases, four cases were the unloading problems and one case was the loading problems. The objective of this article is to summarize the causes of those failures, according to the literature study and to provide some recommendations to prevent similar events happened in the future. The failure of retaining wall is categorized as a geotechnical disaster because it is not only causing major economic losses but also some casualties also been reported. The main reason for the failure was the improper design of the retaining and supporting system. One of the good indication before failure would occur was excessive movements induced by excavation or fill. Hence, it was recommended to install a proper geotechnical instrumentation in the construction and the nearby area. Moreover, an excavation or fill project should be strictly operated and controlled by a safety management to avoid any casualties. The safety regulations should be supported and understood by all of the people involved in excavation or fill projects.
\end{abstract}

\section{Introduction}

According to the World Health Organization [1], a disaster is defined as an occurrence disrupting the normal conditions of existence and causing a level of suffering that exceeds the capacity of adjustment of the affected community. In addition, according to International Federation of Red Cross and Red Crescent Society [2], A disaster is a sudden, calamitous event that seriously disrupts the functioning of a community or society and causes human, material, and economic or environmental losses that exceed the community's or society's ability to cope using its own resources. Though often caused by nature (natural disaster), disasters can have human origins (man-made disaster).

In the viewpoint of geotechnical engineering, many disasters are corresponding to geotechnical failures such as an embankment (dike) failure or an excavation failure; and natural hazards, for example, landslides, rockfall, and earthquake-induced large deformations. This article would focus on failures of retaining wall, either for excavation or fill purposes because most of the excavations are constructed in a dense urban area, where the risk of losing a human life is relatively high. In past decades, several major excavation failures were reported in the literature, such as Nicoll Highway excavation in Singapore [3, 4, 5], Shipai excavation and Rebar Broadway excavation in Taipei $[6,7,8,9,10,11]$. In addition, a case of excessive deformations induced by excavation also recorded in Jakarta back in 1991 and causing the demolishment of the affected building.
The failure of excavations not only causing major economic losses but also some casualties also been reported. Moreover, a case of high retaining wall failure due to erosion at the wall toe also reported here. Hence, the failure of retaining wall could be classified as one of the geotechnical disasters. The objective of this article is to summarize the causes of those failures, according to the literature study and to provide some recommendations to prevent similar events happened in the future.

\section{The collapse of Nicoll Highway excavation}

The Nicoll Highway excavation was located in Singapore and collapsed on April 20th, 2004 at around $3.30 \mathrm{pm}$. The excavation width was $20.1 \mathrm{~m}$ and was planned to construct in 11 stages. The final excavation depth was $33.3 \mathrm{~m}$, but the support system collapsed when the excavation reached $-30.6 \mathrm{~m}$ from the ground surface (stage 10) as shown in Fig. 1. The broken walls fell inward the excavation zone and the support system, which was steel struts, was distorted. The collapsed length was around $30.5 \mathrm{~m}$. According to the Committee of Inquiry report [12], there were four casualties and three people injured because of this event. This excavation failure yielded in obstruction of the water, electric, and gas distribution lines, which affected about 15000 people in the area. Furthermore, two sections of a

* Corresponding author: aswinlim@unpar.ac.id 
nearby bridge had to be demolished and reconstructed because of the damage to soil conditions.

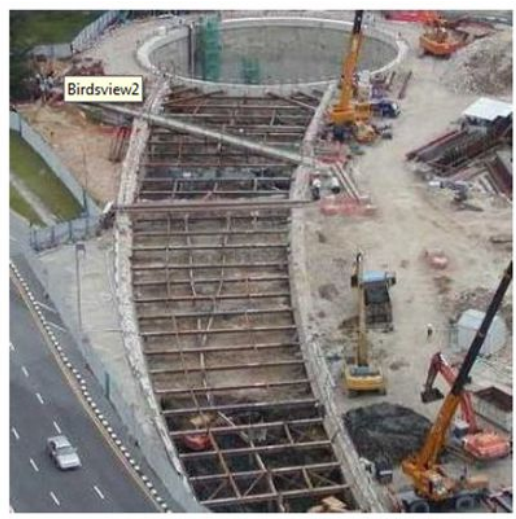

(a). Before collapse

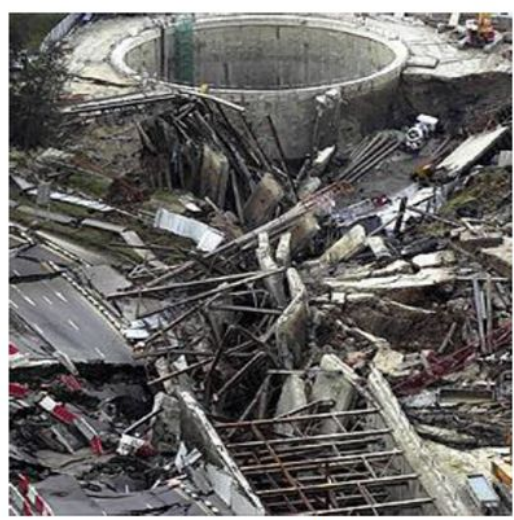

(b).After collapse

Fig. 1. Photo of Nicoll Highway excavation. (a). Before the collapse, (b). After collapse. [12]

The excavation was surrounded by diaphragm walls with $0.8 \mathrm{~m}$ thickness and $44.3 \mathrm{~m}$ in length. In addition, 9 levels of steel struts with $4 \mathrm{~m}$ horizontal spacing and two jet-grouted pile layers were planned for the supporting system. The first layer of the jet-grouted pile was $1.5 \mathrm{~m}$ thick and was temporary and the second layer of the jet grout pile was $2.5 \mathrm{~m}$ thick and formed the base of the tunnel. The purpose of those jet-grouted pile layers was to minimize the deflection of the diaphragm walls while the tunnel was being excavated. As the excavation advanced, the struts were constructed and prior to the construction of the 10th level of the strut, the temporary layer of the jet-grouted pile was removed. Fortunately, this project was heavily instrumented with geotechnical instrumentations, including settlement markers, inclinometers to monitor the soil and wall deflections, vibrating wire piezometers, strain gauges and load cells. The instruments installed in the failed part provided data, which benefit from understanding the reasons for the collapse. Furthermore, the soil conditions consist of 8 layers of clayey and sandy soils, where was predominant by a soft marine clay layer.

According to the Committee of Inquiry report, the failure did not develop suddenly. There were many warnings of approaching collapse but most of the warnings were either not taken seriously or ignored. Some of the events that occurred before the collapse shed some light on the critical error in the design methodology that is the use of effective stress approach (Undrained A) for the design of the diaphragm walls of the temporary retaining wall systems. Before the main failure occurred, excessive ground surface settlement in order of $400 \mathrm{~mm}$ has been detected. Vertical cracks of diaphragm wall panel also clearly observed. This crack was one of indication that the diaphragm wall has reached its capacity. For this reason, the jet-grouted piles were constructed in order to limit the wall deflections. On the day of the main event, the workers at the site heard sounds from the multi-level strut system at around 8 a.m. These sounds were investigated by the senior engineers of the contractor and unfortunately, they found that a lot of the waler-strut connections had undergone yielding. Then, immediate action was executed by evacuating all of the construction workers. In the afternoon, engineers from the owner's side came to the site and along with the contractor's engineers, they decided to pour concrete at the 9th level of the strut for stabilizing the excavation. However, by 3:30 p.m the temporary system failed and causing 4 casualties and 3 people injured.

Official reasons for this collapse are reported by Committee of Inquiry, Ministry of Manpower, Singapore. First, the application of Method A (Effective Stress Method) for designing the diaphragm walls yielded in overestimation of the undrained shear strength. As consequences, it underestimated the diaphragm wall bending moment and wall deflections of about $50 \%$. Second, the under design of the waler-strut connection.

\section{Rebar Broadway excavation failure}

Rebar Broadway excavation is located in Taipei, Taiwan. The shape of the excavation is rectangular (100 $\mathrm{m} \times 26 \mathrm{~m}$ ), as shown in Fig. 2. The excavation was surrounded by the diaphragm wall with 24 meters in length and $0.7 \mathrm{~m}$ in thickness. The final excavation depth was 13.45 meter with the spacing of horizontal bracing was varied from 4.1 meters to 5.8 meters.

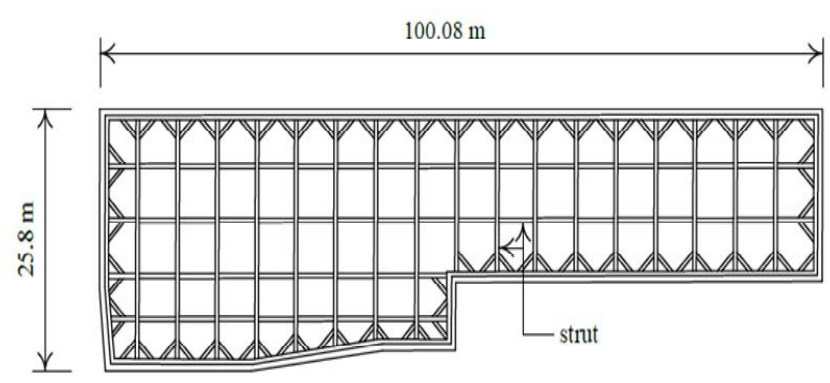

Fig. 2. Excavation plan and arrangement of support system of Taipei Broadway Excavation [6]

Fig. 3 shows the subsoil profile and construction sequence. The excavation site was located in the backfill 
zone of a deserted watercourse. The level above the ground surface (GL) of -8.7 meter was the backfill level. The level ranging from GL -10.7 to -44.7 meter was thick, soft, silty clay (CL). The groundwater level was at about GL -2.8 meter. The basal heave failure occurred about 2.5 hours after the final stage of excavation had been completed and the entire internal bracing system collapsed, as shown in Fig 3.

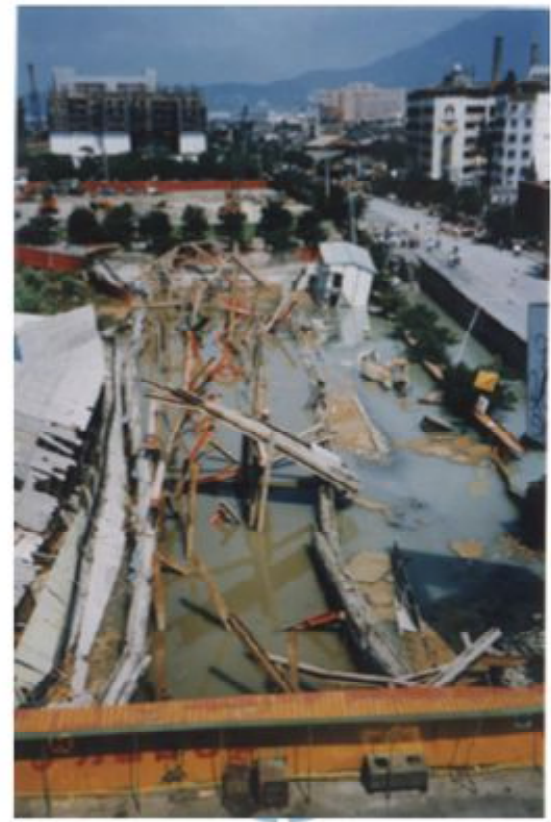

Fig. 3. Photo of Rebar Broadway excavation failure (private document)

As the result of this failure, the affected area covered about 132 meters in length and 40 meters in width. In this case, due to privacy, no information about the casualty, the total loss, or instrumentation data was released. The possible reasons for this failure were investigated using the finite element method [11]. They concluded that it is most likely that the failure was caused by yielding of struts and diaphragm walls.

\section{Shipai excavation failure}

Shipai excavation is also located in Taipei, Taiwan. The shape of excavation is rectangular with 12.3 meters long and 45 meters wide, as shown in Fig 4. The length of the diaphragm wall was varying between 13.8 to 17 meter, the average was 15.4 meter and the thickness was only 0.5 meter. The final excavation depth was 9.3 meter with a horizontal bracing structure.

Fig 5 shows the subsoil profile and construction sequence. The level between GL -5.5 and -4.1 meter was a thick layer of silty clay (CL). The groundwater level was at about -1.5 meter. The basal heave failure occurred when this site was excavated down to the final excavation depth as shown in Figure 6. This failure caused the adjacent building tilted toward the excavation area. Similar to the Rebar Broadway excavation, no information about the casualty, the total loss, or instrumentation data were released. The possible reasons for this failure were also investigated using the finite element method [11]. They concluded that it is most likely

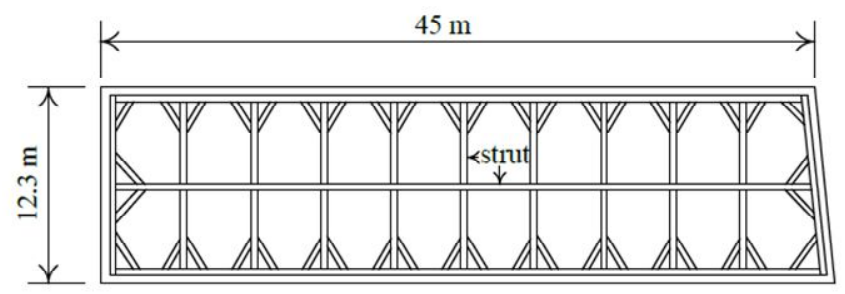

Fig. 4. Excavation plan and arrangement of support system of Shipai Excavation [6]

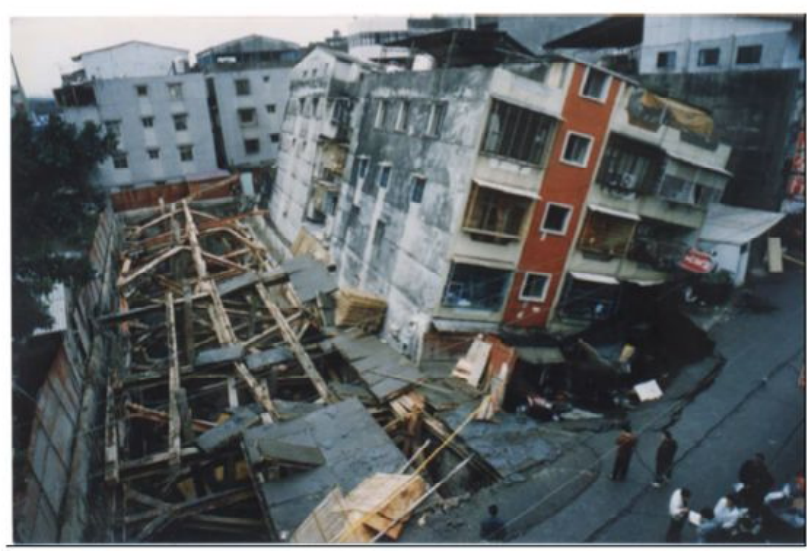

Fig. 5. Photo of Shipai Excavation Failure (Private document)

\section{Case a excavation failure}

Case A excavation is located in North Jakarta where the soil is predominantly soft clay. Indeed, the characteristic of soft clay in North Jakarta was under consolidating [13]. The similar finding also reported by Cox [14]. The depth of this excavation is relatively shallow, which was only $4 \mathrm{~m}$ and the excavation would be utilized for a ground water tank. The excavation was executed using the open cut method, where no retaining wall system was planned. During the excavation, the soil was starting to collapse toward the excavation site. Immediate action was executed by installing bamboo and sheet piles in the surrounding area, and the excavation continued. However, this unplanned temporary retaining wall system could not stop the soil movement. Ten days later, some installed pile foundations which were adjacent to the excavation, prior to construction of pile cap moved $1.0 \mathrm{~m}$ laterally. Due to the large movements occurred at the adjacent structures, the excavation was back-filled with un-compacted fill material. At this time, the soil at the ground surface started to crack. The distance of soil cracking was around 7 to $8 \mathrm{~m}$ or around 2 times of excavation height. On midnight of January 1st to 2nd 1990, the strange sound (similar to a broken sound) was heard three times. At the early morning of January 2nd, 1990, the adjacent office was settled around $140 \mathrm{~mm}$ toward the excavation zone and followed by nearby structures, as shown in Fig 6. Some actions were applied to limit the settlement, such as grouting, but it did not 
show promising results. Then, in March 1991, the owner of the tilt office decided to demolish the tilt office for safety reason.

In this case, it was obvious that the ignorance in the proper design of excavation in soft clay lead to the great financial loss. The key finding, in this case, is due to the fact that the soil is still under-consolidating and existing excess pore pressures pushed the soils to move. Furthermore, Fig 6 also shows that deep sliding occurred due to unprotected excavation and the piles were not designed to bear this additional movement.

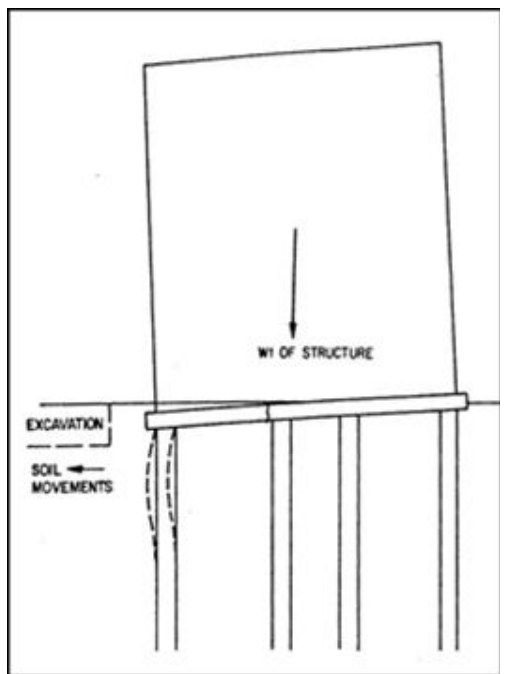

(a). Illustration

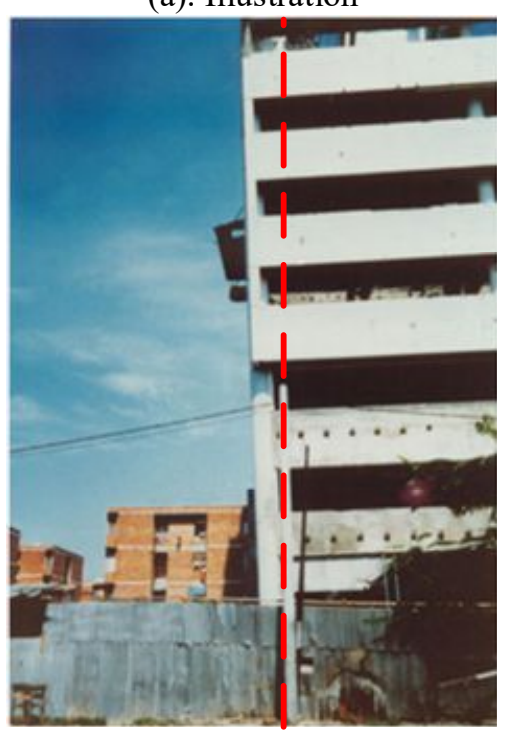

(b). Photo

Fig. 6. Illustration and photo of Case A Excavation Failure [15]

\section{Failure of high-retaining wall in north bandung}

A failure of the high retaining wall also recorded in North Bandung in 2004. The height of the retaining wall is about $20 \mathrm{~m}$ and the toe is sat on Cipaganti riverbank, as shown in Fig 7. The purpose of this retaining wall is to support the existing slope and fill material behind the wall. The fill material was used to raise the elevation for a housing development. The fill material was placed colluvium soil. The incident occurred after a heavy rain the river overflows. It should be noted that the flow of Cipaganti river is very swift during rain. It was suspected that the erosion at the toe of the retaining wall triggered the failure of the retaining wall.

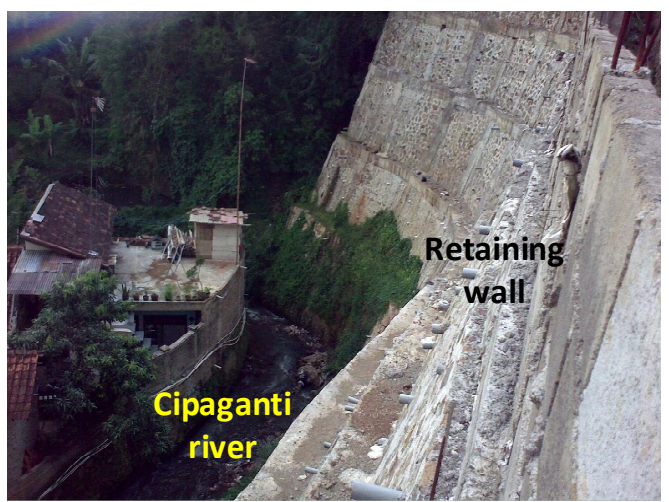

(a). Before failure

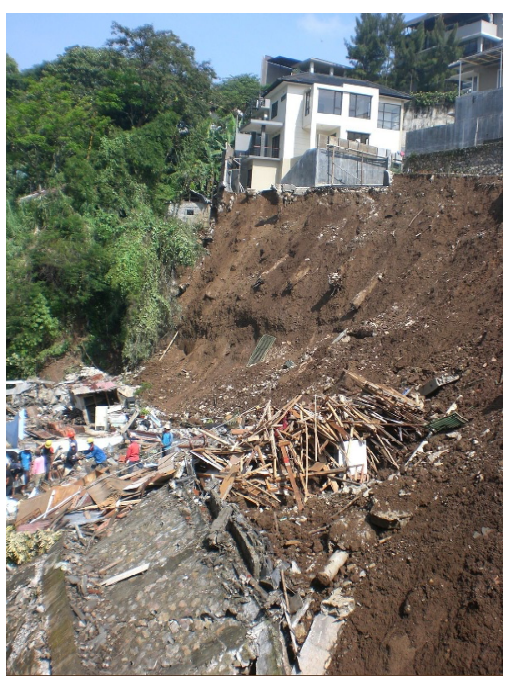

(b). After failure

Fig. 7. Photo of the high retaining wall failure. (a). Before the failure, (b). After failure. (Private document)

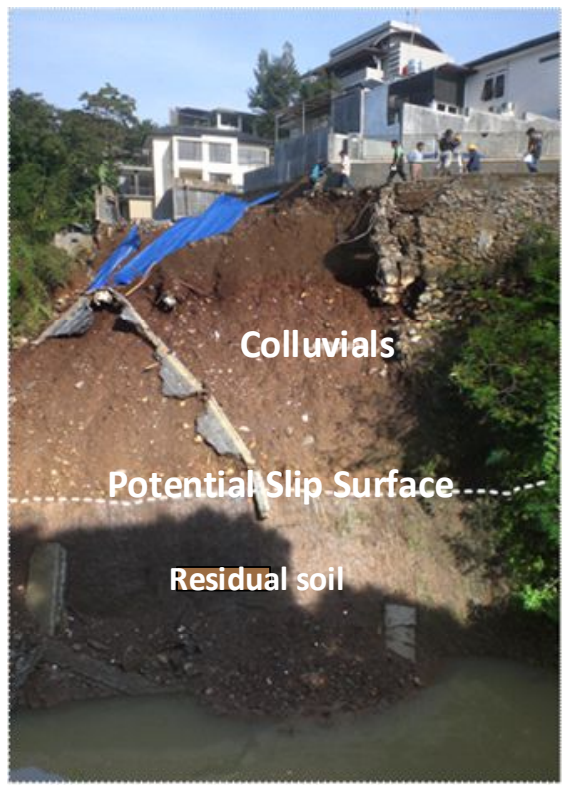

Fig. 8. Photo of the potential slip surface at the interface of fill and residual soil. (Private document) 
In this incident, at least two houses were buried by the fill material and people inside the houses were injured. Fortunately, no casualties were reported. After the geotechnical investigation, a potential slip surface was found in the interface between colluvial and the residual soil, as illustrated in Fig 8. The characteristic of colluvium material is very porous. As a consequence, water could easily infiltrate the fill material. Hence, the usage of colluvium soil as fill material should be treated very carefully. After the incident, the fill materials were excavated and a new system of retaining wall was proposed. The proposal used soldier piles which could penetrate into the residual soil, hence the potential slip surface could be restraint.

\section{Summary and lesson learned}

Based on five retaining wall failure cases, some lessons could be learned to prevent similar incidents happened in the future:

1. That four retaining wall for excavation collapsed in soft soils condition. Excavation planning and construction should be done carefully when dealing with soft soils. It is recommended to involve geotechnical and structural experts in design, construction, and supervision stages to ensure the safety of an excavation in soft soils. A geotechnical and structural monitoring system, for example, inclinometer, settlement markers, load cells, are compulsorily installed at the site. Before an excavation collapse, excessive deformations, for example, soil cracking in the ground surface and large wall deflection, are obviously detected. In addition, the load in the strutting system would reach its yield condition. When such conditions occurred on the site, all of the workers should be evacuated to avoid casualties.

2. No matter the scale of excavation geometry, a temporary retaining wall system should be installed to protect soil collapse. Unprotected excavation, though it is shallow, would also generate excessive deformations, as reported in Case A.

3. An excavation failure in soft soil could be prevented if all of the stakeholders agree to put the safety on the first priority. As consequences, the excavation could be more expensive than the excavation in firm soil. However, it should be noted that remediation after collapse always much expensive than the original planning.

4. A retaining wall for fill purpose also could fail if not designed properly. Colluvial is material that frequently moved during rain and shall not be considered as fill material. The usage of fill material should be carefully decided. More importantly, the retaining wall system should be suitable for the scale of fill material. For the high-retaining wall, the stability at the toe of the retaining wall should be considered by using bored pile, or protected from erosion during the flood.
The authors acknowledge the support provided by Parahyangan Catholic University, Bandung, Indonesia.

\section{References}

1. WHO website. [Online]. Available: http://apps.who.int/disasters/repo/7656.pdf (2018).

2. IFRC website. [Online]. Available: http://www.ifrc.org/en/what-we-do/disastermanagement/about-disasters/what-is-a-disaster/ (2018)

3. A. J. Whittle, R. V. Davies, Nicoll Highway Collapse: Evaluation of Geotechnical Factors Affecting Design of Excavation Support System. International Conference on Deep Excavations, Singapore, 28-30 June 2006.

4. G. Corral, and A. J. Whittle. Re-Analysis of Deep Excavation Collapse Using a Generalized Effective Stress Soil Model. Proceedings of the 2010 Earth Retention Conference, Bellevue, WA, USA. (Geotechnical Special Publications; GSP 208), (2010)

5. A. M. Puzrin, E. E. Alonso, N. M. Pinyol, Braced Excavation Collapse: Nicoll Highway, Singapore. Geomechanics of Failures. 151-181, (2010)

6. P. G. Hsieh, C. Y. Ou, H. T. Liu, Basal heave analysis of excavations with consideration of the anisotropic undrained strength of clay, Canadian Geotechnical Journal, 45(6), 788-799 (2008)

7. A. Lim, C. Y. Ou, Analysis of basal heave stability for excavations in soft clay using the finite element method". Proceedings of the 3rd international conference of European Asian civil engineering forum. G-49 - G-55. Yogyakarta, Indonesia, 20-22 September (2011)

8. T. N. Do, C. Y. Ou, A. Lim, Evaluation of Factors of Safety against Basal Heave for Deep Excavations in Soft Clay Using the Finite-Element Method, Journal of Geotechnical and Geoenvironmental Engineering, 139(12)2125-2135, (2013)

9. C. Hung, H. I. Ling, V. N. Kaliakin, Finite element simulations of deep excavation failures, $J$. Transportation Infrastructure Geotechnology. 1, 34, 326-345, (2014)

10. C. Y. Ou, T. N. Do, Finite element analysis of the failure of deep excavations in soft clay, The 15th Asian Regional Conference on Soil Mechanics and Geotechnical Engineering, Japanese Geotechnical Society Special Publication pp. 1555- 1558. https://doi.org/10.3208/jgssp.ATC6-04, (2015)

11. T. N. Do, C. Y. Ou, R. P. Chen, "A study of failure mechanisms of deep excavations in soft clay using the finite element method" Computer and Geotechnics, 73:153-163, (2016)

12. Committee of Inquiry. Report of the Committee of Inquiry into the incident at the MRT circle line worksite that led to the collapse of Nicoll highway 20 April 2004. Ministry of Manpower, Singapore, (2005) 
13. P. P. Rahardjo, Different Methods of Excavation for Basement in Jakarta: Design, Reality and Associated Problems. Proceedings of the 2nd International Symposium on Asia Urban GeoEngineering, 184203, Changsa, China, November 24-27, (2017)

14. J. B. Cox, The distribution and formation of recent sediments in South East Asia. Proceedings of the 2nd Southeast Asian Conference on Soil Engineering, 29-47, Singapore, (1970)

15. H. Poulos, Evaluation of foundation failures due to excavation in Jakarta, Report submitted to the owner and contractor, (1991) 